\title{
Should Hungary Pay More for a QALY Gain than Higher-Income Western European Countries?
}

\author{
Sándor Kovács ${ }^{1,2} \cdot$ Bertalan Németh $^{2} \cdot$ Dalma Erdősi ${ }^{1} \cdot$ Valentin Brodszky ${ }^{3} \cdot$ Imre Boncz $^{4} \cdot$ Zoltán Kaló $^{2,5}$. \\ Antal Zemplényi ${ }^{1,2}$ (-)
}

Accepted: 29 November 2021 / Published online: 18 January 2022

(c) The Author(s) 2022

\begin{abstract}
Objectives Cost-effectiveness thresholds (CETs) play a particularly important role in the reimbursement decisions of health technologies in countries with limited healthcare resources. Our goal is to develop a scientifically solid proposal for a revised cost-effectiveness threshold, as part of the planned review of the Hungarian health economic guidance.

Methods The Threshold Working Group of the Hungarian Health Economics Association performed a targeted review on CETs in European countries. International trends on CETs served as a basis for our recommendation, which was discussed at the Association's workshop and deliberated at an expert committee meeting with representatives from the national health technology assessment (HTA) and healthcare payer bodies, and academic HTA centres.

Results The current Hungarian CET is one of the highest among European countries relative to GDP per capita, and even higher in nominal value than the CET applied by NICE. As opposed to the current, single Hungarian threshold, other European countries apply multiple thresholds. The Working Group recommends that Hungary should also apply multiple CETs in the range of 1.5-3 times GDP per capita with stratification according to the relative quality-adjusted life-year (QALY) gain of the new technology. In addition, multiple CETs in the range of 3-10 times GDP per capita is recommended for technologies in rare diseases.

Conclusions CETs should be aligned with the country's economic performance and should reflect societal preferences. Our recommendation may increase the efficiency of healthcare resource allocation in Hungary by strengthening the role of HTA in the reimbursement decisions and favouring new technologies with higher QALY gain.
\end{abstract}

Antal Zemplényi

zemplenyi.antal@pte.hu

1 Division of Pharmacoeconomics, Faculty of Pharmacy, University of Pécs, Pecs, Hungary

2 Syreon Research Institute, Budapest, Hungary

3 Department of Health Economics, Corvinus University of Budapest, Budapest, Hungary

4 Institute for Health Insurance, Faculty of Health Sciences, University of Pécs, Pecs, Hungary

5 Centre for Health Technology Assessment, Semmelweis University, Budapest, Hungary

\section{Key Points for Decision Makers}

Our study provides a comprehensive overview of recent cost-effectiveness thresholds, and contains information on Central and Eastern European countries, which are cited less frequently in the literature.

Cost-effectiveness thresholds in relation to GDP per capita in Central and Eastern European countries, and particularly in Hungary, are higher compared with Western European countries.

The baseline cost-effectiveness threshold in Hungary was proposed to be lowered and equity considerations regarding severity and rarity of the diseases were recommended to be introduced. 


\section{Introduction}

Policy makers all over the world are struggling with developing transparent and verifiable approaches to allocate scarce healthcare resources to the most valuable technologies. Several countries have adopted mandatory cost-effectiveness analysis to inform coverage decisions, where health gains are expressed as quality-adjusted life-years (QALYs). Incremental cost-effectiveness ratios without a cost-effectiveness threshold (CET) cannot determine whether the gain from a new technology is worth paying for, as decision-makers need to know the maximum amount of incremental financial resources that is considered appropriate to pay for one additional unit of health gain [1].

To manage increasing demands is a particular challenge in countries with limited financial resources compared with more affluent countries in Western Europe or North America. Although Hungary implemented mandatory health technology assessment (HTA) methodologies starting from 2004, including cost-effectiveness analysis to support pricing and reimbursement decisions of new pharmaceuticals and later expanded this to medical devices as well [2], the potential to support efficient resource allocation has not been fully realised.

In the initial period only an implicit CET was applied in Hungary, then in the 2011 update of the methodological guidelines the conventionally used two to three times the gross domestic product (GDP) per capita per QALY gained threshold was published by the Ministry of Human Resources [3]. From 2017, the lower threshold was eliminated from the methodological guidelines, and only the single CET of three times GDP per capita $(44,845 €$ in 2019) has been applied [4]. With the economic growth in Hungary, the actual threshold has grown over the years, and has even surpassed the constant thresholds in Western European countries. To put this into context, the National Institute for Health and Care Excellence (NICE) in England has used an explicit and constant CET of between 20,000 and £30,000 GBP per QALY gained [5], which has not been changed with the growth rate of the British economy. The NICE thresholds correspond to $22,785 €$ and $34,178 €$ in 2019 in actual exchange rate, the lower bound is $51 \%$ and the upper bound is $76 \%$ of what is used in Hungary for coverage decisions (see Fig. 1).

This difference between the two countries is particularly striking when we also take into account that per capita GDP in Hungary was $40 \%$ of that in the UK in average between 2011 and 2019. It is worth noting that the Hungarian policy-making practice of reducing the number of CETs goes against the international trends and even the UK practice. In the UK end-of-life criteria were introduced in 2009 and the practice has led to the application of a maximum weight of 2.5 from a starting point of $£ 20,000$ per QALY $[7,8]$. In 2017 further thresholds were introduced for highly specialised technologies (HST), treatments for very rare conditions and fast-track medicines ( $£ 100,000$ per QALY $-320 \%$ of the GDP per capita), which can be increased up to $£ 300,000$ (960\% of the GDP per capita) in case of curative therapies with over 30 QALY gain [9]. A comparison of the Hungarian and UK CETs between 2011 and 2019 is shown in Fig. 2.

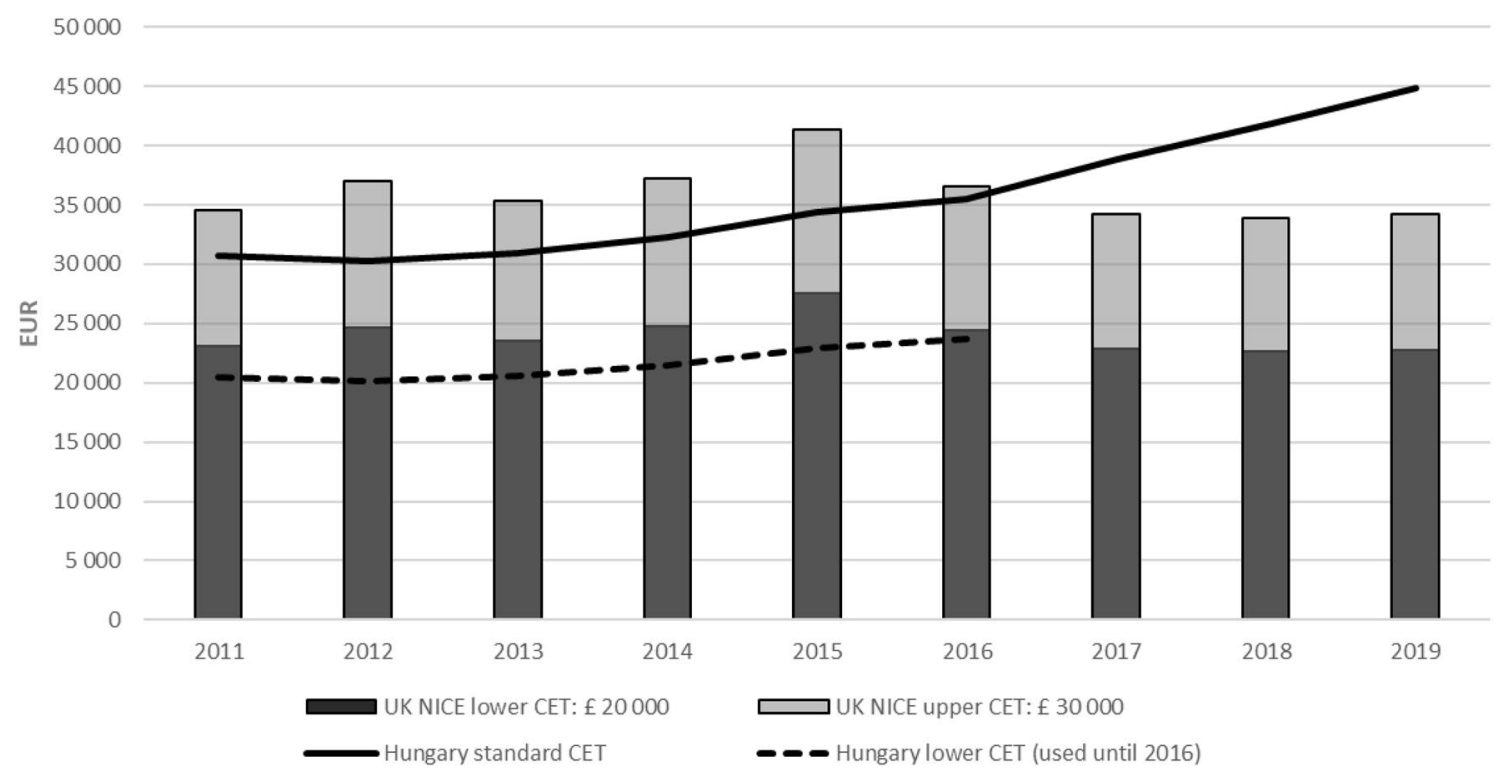

Fig. 1 Actual value of the Hungarian CETs compared to the general UK NICE CETs between 2011 and 2019 in Euro. CET cost-effectiveness threshold, NICE National Institute For Health and Care Excellence. Source of exchange rates: [6] 


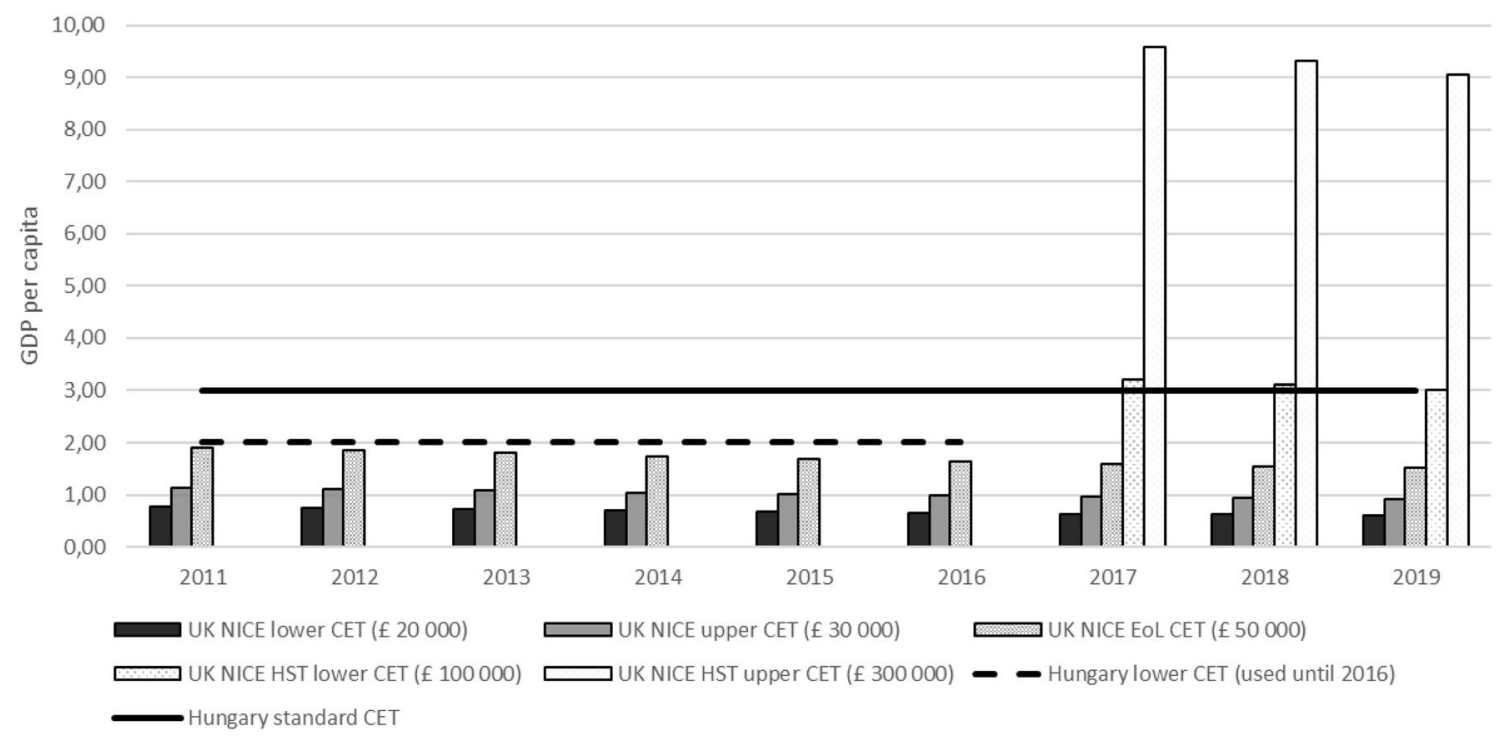

Fig. 2 Hungarian and UK NICE CETs between 2011 and 2019 relative to the GDP per capita. CET cost-effectiveness threshold, EoL end-of-life, HST highly specialised technology, NICE National Institute For Health And Care Excellence. Source of GDP per capita: [10]

Setting the appropriate CET is challenging. If the threshold is set too low, treatments with good value for money will be rejected, resulting in a loss of health for the society [1]. On the other hand the very high CET leads both to the inefficient allocation of resources [11] and to a suboptimal functioning of HTA in supporting coverage decisions, as technologies might easily meet the cost-effectiveness criteria but will still not be reimbursed [12] or will be reimbursed with hidden restrictions $[13,14]$ due to unaffordability caused by the budget constraints, the primary cause of patient access limitations [15]. Therefore, CET needs to be better aligned with the country's financial resources to help meet the payer's requirement to maximise health from the budget available for the introduction of new technologies.

The other concern with the Hungarian CET is that the application of a rigid single threshold does not allow the use of the HTA framework for adopting highly specialised technologies (e.g., orphan medicines for treating ultra-rare diseases), which are very expensive and likely cannot meet the cost-effectiveness criterion. Consequently, in Hungary these technologies are reimbursed without any judgement on the value-based price often on a named patient basis [16].

Due to the expiry of the current guidance at the end of 2020, the College of Healthcare Professionals established a Guideline Revision Committee (VB, IB, ZK, AZ and eight other non-author members) to update the "Guideline for Economic Evaluations in Healthcare in Hungary" [4]. Members were appointed by the College of Healthcare Professionals (institution of Health Care State Secretariat of the Ministry of Human Capacities) representing academia, National Health Insurance Fund, and the national HTA agency in Hungary. The head of the national HTA Agency chaired the Committee. As part of this work, the Committee asked the Hungarian Health Economics Association (ISPOR Hungary Chapter) to lay out new recommendations for a revised CET in Hungary.

The current study is a summary of the work of the Association's Threshold Working Group (SK, BN, DE, AZ and two other non-author members) to provide a scientifically sound basis for developing recommendations. The objective of this work was threefold. The main aim of this work was to provide recommendations for a new CET to be used for evaluating cost-effectiveness in the Hungarian healthcare system. In order to develop an informed proposal, it was necessary to know the practices of other countries in setting thresholds. Therefore, the second aim of the work was to collect the explicit values of CETs from the CEA guidelines in the European countries and assess how these relate to the countries' GDP per capita, a proxy for economic constraints on health spending. In this way, we can assess how the Hungarian threshold compares with thresholds in other European countries. The other aim was to review what additional factors were taken into account when assessing the cost-effectiveness of a technology, represented by the criteria used to apply multiple CETs.

\section{Methods}

\subsection{Identification of Guidelines}

We identified HTA agencies in Europe using a list from a recently published review [17]. For each HTA agency, we searched the websites, looking for publicly available 
methodological guidance (in any language), either as guidelines or as methodological advisory documents. For countries where such documents were not available, local experts were asked to provide references for documents describing the value of CET. The participants were identified in an iterative process in which the professional networks of the Threshold Working Group were used. The main selection criteria were familiarity with cost-effectiveness thresholds and HTA in their own country. Overall, nine experts from the Czech Republic, Denmark, Ireland, Lithuania, Poland, Romania, Slovenia and Slovakia contributed to the process.

\subsection{Document Review and Data Extraction}

After identifying the relevant documents, the following data were extracted for each country: (1) name, year and website location of the guidance document, (2) language of the document, (4) text related to CETs, (5) text on the criteria for multiple thresholds, and (6) values and units of CETs. A data-extraction form was developed and tested by two authors (SK and AZ) on a sample of documents in English and Hungarian to check the feasibility of the process and to ensure that the data collected was suitable and sufficient for the aim of the study. Members of the Thresholds Working Group between May and July 2020 then used the revised extraction form. Two senior reviewers (AZ, SK) then compared the extracted data with the original documents. The threshold values used in 2019 were converted to Euros based on the annual exchange rate in 2019. GDPs of the countries in 2019 were extracted from EUROSTAT and OECD databases. The review of the guidelines was complemented by a review of scientific articles on CETs in European countries to gain a deeper understanding of current trends in the evolution of CETs in this region and an explanation on the rationale for changes. As our aim was to analyse CETs from original sources, we present the results of the data obtained from the guidelines only.

\subsection{Development of Recommendations}

The development of the proposal for the Hungarian CET was carried out in four consecutive steps. First, the Threshold Working Group summarised the findings of the review of guidance documents, agreed on principles to be considered, and proposed options for the use of the CETs. Participants were senior health economists from university centres and pharmaceutical companies with extensive experience in conducting economic evaluations.

Second, the results of the review and the proposed options for CETs were presented and discussed in detail at a public forum of the Hungarian Health Economics
Association in June 2020. Attendees were voluntary experts representing multiple stakeholder groups, including academia, institutes in the public sector, the healthcare industry and market access consultants. The presentation was followed by an open discussion, where participants made comments and suggestions on what preferences should be considered when setting the value of CETs. These were then summarised by the Threshold Working Group and used to describe the key principles to be considered when developing alternative options for the new CETs. The summary document was made publicly accessible on the Association's website (www.metaweb.hu).

In a third step, the proposed principles and options were presented to the Guideline Revision Committee, which held three online meetings between July and September 2020, where members shared their views, suggested further options, requested additional data analysis, and made textual recommendations on the content of the text related to CETs. The trade-offs of the alternative options were then carefully considered. Reaching consensus was facilitated by the chair of the Working Group (the president of the Hungarian Health Economics Association), who produced a single working document that reflected the advantages and disadvantages of each approach. The working document was presented to the group, iteratively discussed, and narrowed down to one approach until full consensus was reached within the group. Historical data on QALY gains were analysed: the absolute and relative differences in QALYs were calculated based on all HTA dossiers at the national HTA agency in the last 12-month period (i.e., between July 2019 and June 2020) and the distribution of health gains for those recently assessed technologies was examined to simulate the impact of introducing health gains as a criterion for using different levels of CETs. After evaluating the results of the simulations, the recommendations for the CETs were further refined by consensus of the Committee participants.

Fourth, the draft recommendations were then shared in a report format with the representatives of 12 organizations in November 2020, who were invited based on their expertise or involvement in HTA processes. These included HTA and reimbursement decision-makers, pharmaceutical and medical device manufacturers, healthcare providers, consulting companies, and patient organizations. A second public forum was held to clarify stakeholder questions on the draft recommendations. Ten out of the 12 major associations of these stakeholders submitted written feedback as part of the public consultation. These were then evaluated by the Revision Committee and a decision was made by consensus as to which recommendation should be accepted, accepted with changes, or rejected. The final responses were provided to each stakeholder group in written form. 


\section{Results}

\subsection{Review of Guidelines}

The search of HTA agencies' websites and the information provided by local experts led to the review of CETs from 26 countries. No guidelines could be found in six of the countries examined (Croatia, Denmark, Greece, Malta, Romania, Spain) and there were eight countries (Austria, Belgium, Finland, France, Germany, Italy, Portugal, Switzerland), where no explicit values for the CET were given in the guidelines. In the latter group of countries, CET is either implicit or they use different approaches to support reimbursement decisions (e.g., clinical effectiveness, market price, budgetary impact, etc.). Twelve countries provided information on the CETs in guidelines for the economic evaluation of health technologies. These are summarised in Table 1. More detailed information on the original sources of CETs can be found in the Electronic Supplementary Material S1.

\subsection{Threshold Relative to GDP}

CETs should be related in some way to the health budget, whether it is fixed or flexible, and the health budget is mainly determined by the economic constraints of the country, for which GDP per capita is a good proxy indicator. CETs in relation to the GDP per capita were compared to benchmark with regard to how much the economic constraints of the countries differ and to what extent the thresholds follow these ratios.

While all (5/5) of the higher income countries (i.e., higher GDP per capita than the EU-28 average in 2019, 28,610 € [28]) use multiple level thresholds, most (6/7) of the countries with lower GDP per capita (i.e., lower GDP per capita than the EU-28 average) tend to use a single CET (except for Lithuania). In Central and Eastern European (CEE)

Table 1 Thresholds stated in official guidelines (both single and multiple thresholds)

\begin{tabular}{|c|c|c|c|c|c|c|c|}
\hline Country & ISO country code & Levels of thresholds & $\begin{array}{l}\text { Value as originally } \\
\text { stated }\end{array}$ & $\begin{array}{l}\text { CET in EUR (with } \\
\text { actual exchange } \\
\text { rate) }\end{array}$ & GDP per capita & $\begin{array}{l}\text { Threshold/ } \\
\text { GDP per } \\
\text { capita }\end{array}$ & Source \\
\hline Czech Republic & CZE & Single & $1,200,000 \mathrm{CZK}$ & 44,843 EUR & 18,330 EUR & 2.4 & [18] \\
\hline Hungary & HUN & Single & $3 \times$ per capita GDP & 39,540 EUR & 13,260 EUR & 3.0 & {$[4]$} \\
\hline \multirow[t]{2}{*}{ Ireland } & \multirow[t]{2}{*}{ IRL } & Low & 20,000 EUR & 20,000 EUR & \multirow[t]{2}{*}{ 60,170 EUR } & 0.3 & \multirow[t]{2}{*}{ [19] } \\
\hline & & High & 45,000 EUR & 45,000 EUR & & 0.7 & \\
\hline Latvia & LTA & Single & $3 \times$ per capita GDP & 37,530 EUR & 12,510 EUR & 3.0 & [20] \\
\hline \multirow[t]{3}{*}{ Lithuania } & \multirow[t]{3}{*}{ LTU } & Low & $1 \times$ per capita GDP & 14,010 EUR & \multirow[t]{3}{*}{ 14,010 EUR } & 1.0 & \multirow[t]{3}{*}{ [21] } \\
\hline & & Middle & $3 \times$ per capita GDP & 42,030 EUR & & 3.0 & \\
\hline & & High & $5 \times$ per capita GDP & 70,050 EUR & & 5.0 & \\
\hline \multirow[t]{2}{*}{ Norway } & \multirow[t]{2}{*}{ NOR } & Interval low & $275,000 \mathrm{NOK}$ & 30,730 EUR & \multirow[t]{2}{*}{ 69,560 EUR } & 0.4 & \multirow[t]{2}{*}{ [22] } \\
\hline & & Interval high & $825,000 \mathrm{NOK}$ & 91,191 EUR & & 1.3 & \\
\hline Poland & POL & Single & 147,024 PLN & 33,188 EUR & 13,000 EUR & 2.6 & [23] \\
\hline \multirow[t]{2}{*}{ Slovakia } & \multirow[t]{2}{*}{ SVK } & Interval low & $\begin{array}{l}28 \text { times the average } \\
\text { weekly wage }\end{array}$ & 28,364 EUR & \multirow[t]{2}{*}{ 15,860 EUR } & 1.8 & \multirow[t]{2}{*}{ [24] } \\
\hline & & Interval high & $\begin{array}{l}41 \text { times the average } \\
\text { weekly wage }\end{array}$ & 41,533 EUR & & 2.6 & \\
\hline Slovenia & SVN & Single & 25,000 EUR & 25,000 EUR & 20,700 EUR & 1.2 & [25] \\
\hline \multirow[t]{3}{*}{ Sweden } & \multirow[t]{3}{*}{ SWE } & Low & $100,000 \mathrm{SEK}$ & 9800 EUR & \multirow[t]{3}{*}{ 43,920 EUR } & 0.2 & \multirow[t]{3}{*}[26]{} \\
\hline & & High & $500,000 \mathrm{SEK}$ & 49,000 EUR & & 1.1 & \\
\hline & & Very high & $1,000,000$ SEK & 98,000 EUR & & 2.2 & \\
\hline \multirow[t]{3}{*}{ The Netherlands } & \multirow[t]{3}{*}{ NLD } & Low & 20,000 EUR & 20,000 EUR & \multirow[t]{3}{*}{ 41,870 EUR } & 0.5 & \multirow[t]{3}{*}{ [27] } \\
\hline & & Middle & 50,000 EUR & 50,000 EUR & & 1.2 & \\
\hline & & High & 80,000 EUR & 80,000 EUR & & 1.9 & \\
\hline \multirow[t]{3}{*}{ UK (NICE) } & \multirow[t]{3}{*}{ GBR } & Interval low & $20,000 \mathrm{GBP}$ & 22,400 EUR & \multirow[t]{3}{*}{ 32,910 EUR } & 0.7 & \multirow[t]{3}{*}[7,8]{} \\
\hline & & Interval high & 30,000 GBP & 33,600 EUR & & 1.0 & \\
\hline & & End-of-life & $50,000 \mathrm{GBP}$ & 56,000 EUR & & 1.7 & \\
\hline
\end{tabular}

Note: CET value per GDP per capita was calculated as the ratio of the actual CET and the GDP per capita in 2019. Some countries (e.g.) Poland have originally set the CET value based on the GDP (three times per capita GDP), but as the GDP of the country increased and the nominal value of the CET did not change the ratio decreased to 2.6. Source of exchange rates [6] 


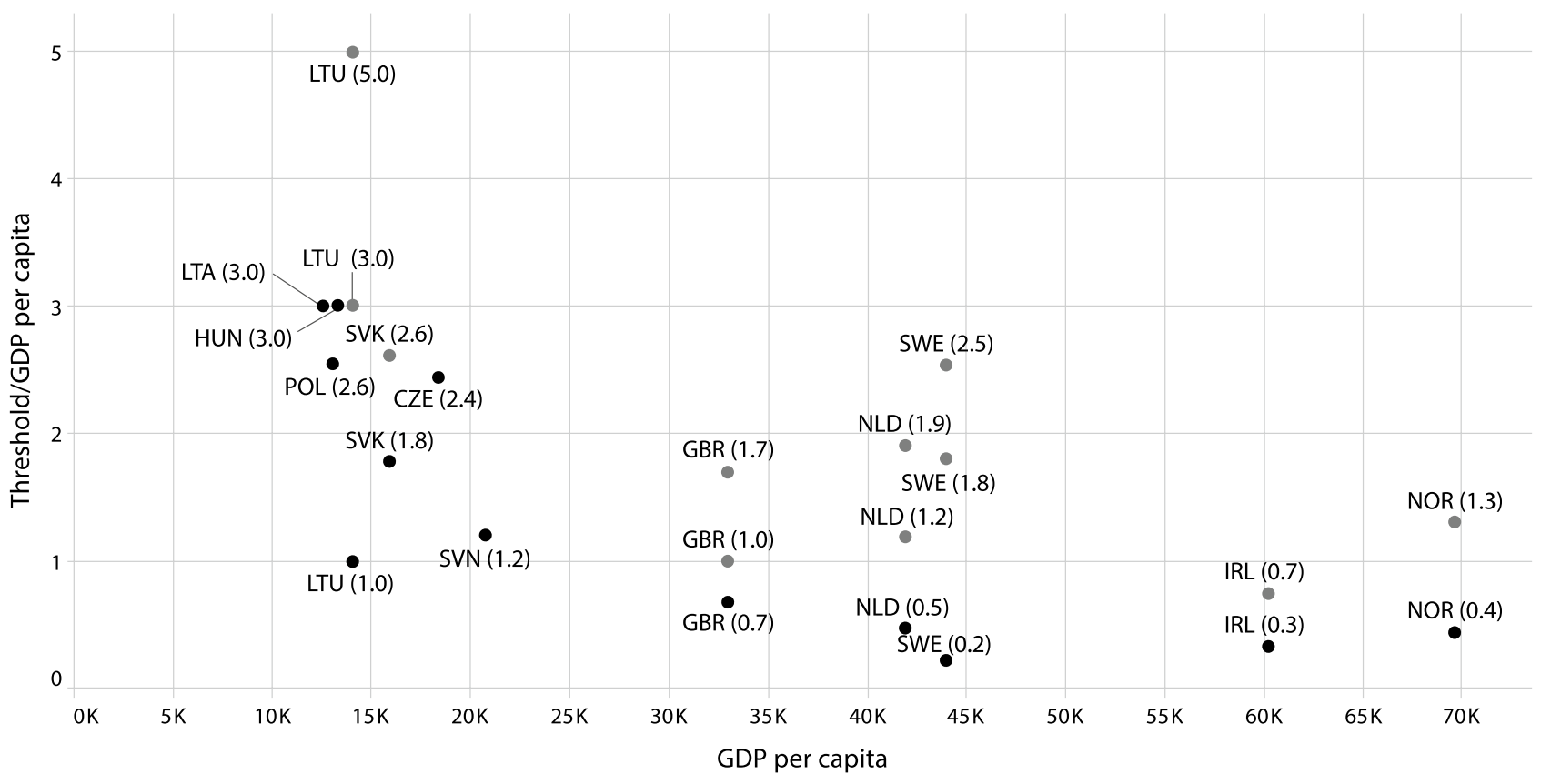

Fig. 3 Cost-effectiveness thresholds per GDP per capita (including multiple thresholds) vs. GDP per capita. Note: Black dots represent either the single CET or the lowest value of CET if multiple thresh-

countries the CET in relation to the GDP per capita tends to be higher compared with higher income countries (see Fig. 3).

The current CET in Hungary is not only higher in nominal value than the threshold applied by NICE and SMC in the UK, but it is one of the highest among European countries relative to GDP per capita (except for the highest threshold used in Lithuania, under certain conditions). The high value of the CETs in most of the CEE countries is especially noticeable if we depict the lowest levels of the CETs used in each country (black dots in Fig. 2). Above these levels, reimbursement is not guaranteed. The assessment of the cost-effectiveness of a technology is judged against criteria that apply to the use of higher-level CETs (such as in the Netherlands, Norway, Lithuania, etc.). This suggests that CEE countries (and Hungary in particular) have set minor barriers to technologies to meet the requirement of proving to be cost-effective.

\subsection{Use of Multiple Thresholds}

Several countries have adopted the idea that it would be inappropriate to use a single threshold to decide whether to include new technologies in the reimbursement scheme [29], incorporating equity considerations in their funding decision. Therefore, they have proposed the use of multiple-level thresholds or scales of ceilings as references for the ICER (see Table 2). Main factors considered for using olds are used. GBR United Kingdom, HUN Hungary, IRL Ireland, LTU Lithuania, LTV Latvia, NLD The Netherlands, NOR Norway, $P O L$ Poland, SVK Slovakia, SVN Slovenia, SWE Sweden

higher thresholds were: burden of the disease, expressed as absolute or proportional shortfall of QALYs; rare disease designation; and end-of-life treatment status. This means that some societies' willingness to pay for an additional QALY is likely higher for direct life-saving treatments than for interventions that target milder diseases or that slightly reduce the risk of an otherwise healthy population. However, definite conclusions on this can only be made after a thorough investigation of the preferences of the members of societies.

The lower limits of multilevel thresholds range from 0.3 to 1.8 times the GDP per capita, while the highest boundaries are between 0.7 and 5.0 times (10.2 for rare diseases) the GDP per capita. Thresholds higher than 1.8 times the GDP per capita are only used when the relative (or absolute) health gain is high. Therefore, those who are more seriously ill are guaranteed a greater share of the resources.

\subsection{Proposal for the Hungarian Cost-Effectiveness Threshold (CET)}

Based on the results presented in Sects. 3.2 and 3.3, the Threshold Working Group identified two major problems related to the Hungarian CET, which need to be addressed: (1) it is too high compared to other European countries, 2) it does not reflect other healthcare priorities. 


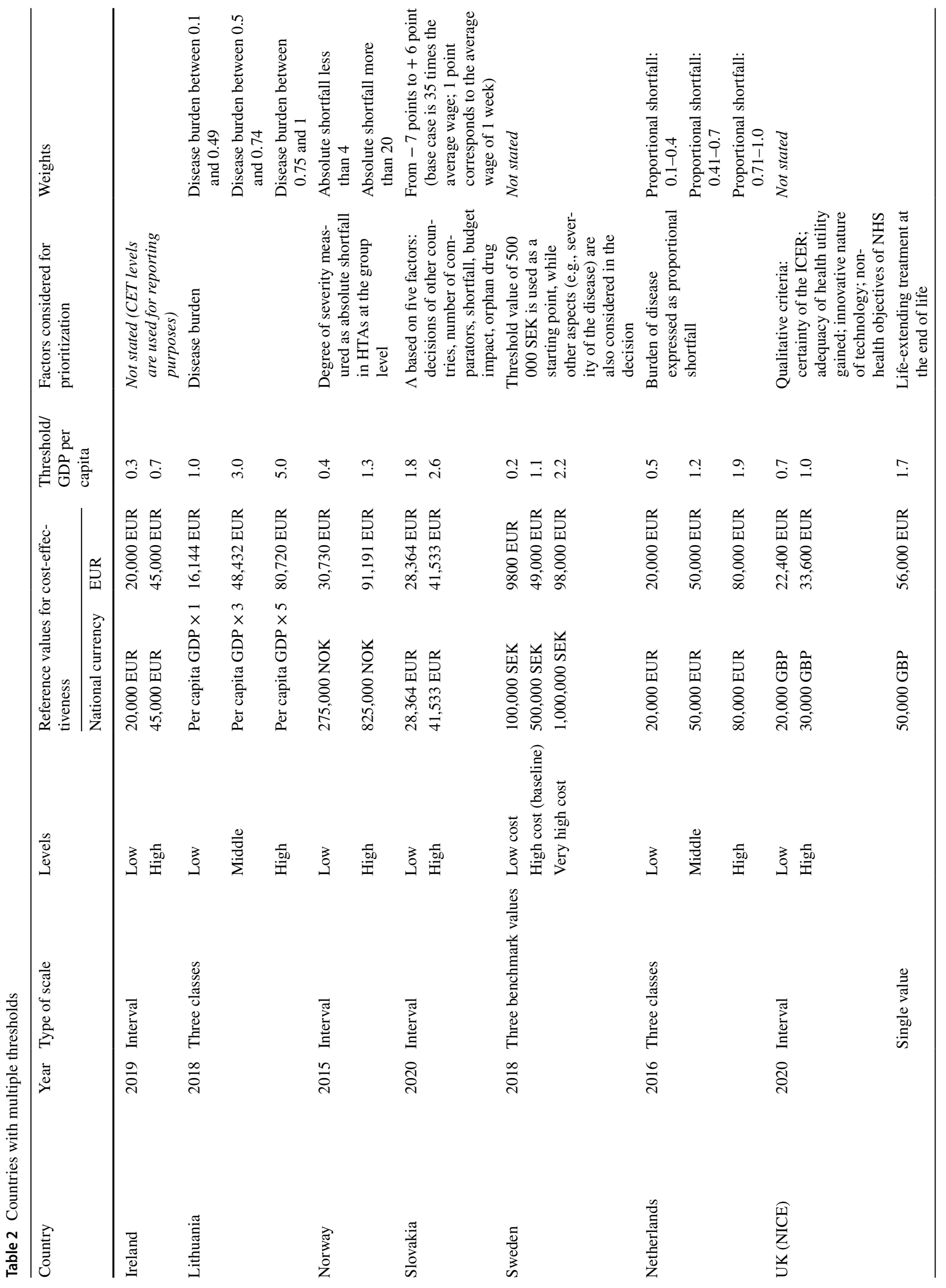


The review revealed that CET in Hungary is not only higher than that of the UK, but relative to the GDP per capita, it is higher than explicit CETs in most of the other European countries. The health expenditure as a share of GDP in Hungary in 2019 is only about $6.4 \%$, far below the EU 27 average of $8.3 \%$ [30]. Given that health expenditure as a share of GDP is already low in Hungary, a high threshold to the GDP per capita (i.e., three times the GDP per capita) leads to an unfair spending structure. This is because although new technologies might be nominally 'cost-effective' according to the CET criterion, not every new technology that achieves this will be affordable, and decisions are ultimately made based on lobbying by certain interest groups. In order to take into account the resource constraints, the Revision Committee concluded that Hungarian CET should be reduced for the majority of health technologies and therefore suggested to set the reference CET to 1.5 times the GDP per capita, which is in nominal value $(22,422$ EUR) similar to what is used in Western European countries (see Table 2), hence it would be difficult to challenge its acceptance by different stakeholder groups.

\subsubsection{Equity Considerations}

The lower level of CET itself does not fully represent the societal preference of a more equitable distribution of health and healthcare. Much of the literature suggests that resource allocation decisions should also take into account the relative social value of QALYs in different population groups [31-34], which implies different threshold values for different QALYs [35]. A quantitative approach to adjust CETs to represent social values is equity weighting [36], which attributes more or less importance to health benefits relative to others. The factors used for equity weighting (see Table 2) in other countries were heavily discussed in the public forums held by the Working Group, and a consensus was drawn that the Revision Committee should incorporate two factors of equity distribution in the new proposal of CETs: severity and rarity of the diseases.

\subsubsection{Severity Factor}

Life expectancy in Hungary lags several years behind most EU countries, due to higher death rates from cardiovascular diseases and cancer [37]. Health gains accrued to worse-off population groups might be valued more by society [22], the Revision Committee therefore preferred the concentration of funding to technologies that provide a relatively higher proportion of health to severely ill patients, in order to narrow the gap with the EU in this way. Severity is usually defined in terms of the pre-treatment health state of patients or the 
expected QALY in case of no treatment (i.e., future health prospect) [35].

As shown by the practice in Lithuania [21], Norway [22], the Netherlands [27], Slovakia [24] and the UK [5, 7], multiple thresholds allow for incorporating equity weights into the reimbursement decision. The Revision Committee therefore suggested that Hungary should apply multiple CETs, where technologies with high relative health gains should be assessed against the upper bound of CET (i.e., the current threshold of three times per capita GDP), while other technologies with less relative benefits should meet the new, reduced reference criteria (1.5 times per capita GDP) for gaining reimbursement.

The review showed that absolute and proportional shortfall are approaches to obtain weights for adjusting the ICER threshold. The concept of 'proportional shortfall' was commonly referred to as a useful approach to quantify severity [38-40]. It proposes that priority should be determined by the proportion of QALYs that people lose relative to their remaining life expectancy due to some illness. The approach of shortfall (either absolute or proportional) requires detailed, up-to-date information in age groups on the potential life-years lost in the country due to the different diseases. This information is currently not available in Hungary. The Revision Committee acknowledged the potential benefits of proportional shortfall and proposed a conceptually similar but simpler equity approach, which can be calculated from traditional economic evaluations without any further research or workload.

The Committee suggested setting priorities based on the incremental relative QALY gains (IRQG), where the numerator is the effect size (difference in QALY of new and comparator treatment), and the denominator is the expected QALY provided by the new treatment:

$\mathrm{IRQG}=\frac{\mathrm{QALY}_{\text {new technology }}-\mathrm{QALY}_{\text {comparator }}}{\mathrm{QALY}_{\text {new technology }}}$

A large incremental QALY represents meaningful improvement in health. A relative measure was proposed to be used for most of the technologies as this way the priority of end-of-life treatments will not be marginalised. As such IRQG relies on not only the superiority of a new technology to the comparator, but also reflects the magnitude of the potential improvement relative to the total QALYs, a higher IRQG can be achieved with smaller incremental QALYs in diseases with less expected QALYs.

\subsubsection{Analysis of Historical Data on QALYs}

Cut-off points were set based on the cumulative distribution of IRQGs in recent HTA dossiers. The quantitative analysis showed that the median IRQG was 0.25 , which is very low, suggesting that the majority of medicines are similar or marginally better than the comparator. The Working Group proposed using the new reference CET (1.5 x GDP per capita) for technologies with relatively low marginal health gain (IRQG $\leq 0.25$ ). This means that ceteris paribus around $50 \%$ of the technologies would have to be assessed against the new reference CET. As only a small majority of technologies proved to be truly innovative with high relative marginal health gain, the Working Group suggested using the upper CET ( 3 x GDP per capita) for technologies with IRQG $>0.60$, which was only reached by $12 \%$ of the technologies in the last 12 -month period. Technologies between the two cut-off points $(0.25$ and 0.60 ) were proposed to be assessed against a mid-level CET (2 x GDP per capita).

\subsubsection{Rarity Factor}

The literature demonstrates that some countries assess the value of new drugs for rare diseases differently from technologies for more common diseases, due to unmet need, the emotional nature of neglected diseases, and higher patient expectations [41-44]. The Revision Committee recognised that drugs developed for rare patient populations require a different approach for HTA and concluded that a separate, higher threshold range should be set for orphan medicines, and the CET threshold should be proportional to the absolute health gain, similar to the practice by NICE. The increased threshold positively discriminates patients with rare diseases, and orphan medicines can be included in the positive drug list after proper HTA instead of the current reimbursement method based on the named patient basis, which creates a significant administrative burden for healthcare professionals, patients and the national healthcare payer.

For orphan medicines with EMA designation the Working Group suggested using the absolute incremental QALY gain (difference in the expected QALYs of the new and comparator therapy), as this indicator directly reflects hope for improved longevity of life or quality of life (QoL) gain for the families of paediatric patients with rare diseases, which is a priority area in the light of forthcoming medical technologies (e.g., advanced therapy medicinal products (ATMPs) in spinal muscular atrophy (SMA)). The Revision Committee concluded that for incremental discounted QALY gains of 0.5 or less, the threshold should be three times GDP per capita (equal to the upper level of CETs for other technologies). For incremental discounted QALY gains above 0.5 and below 20, the threshold should range proportionally between three times and ten times GDP per capita. For 20 or more incremental discounted QALY gains, the threshold should be ten times GDP per capita. 


\section{Discussion}

The role of CET is somewhat different in the reviewed countries. In some countries, it is actually a hard rule on the reimbursement of new technologies, while in other countries it is used as a soft tool to inform the decision maker and support negotiation about the actual price of new technologies. Other factors can also be considered when deciding whether to adopt a technology into the reimbursement system. However, without considering cost-effectiveness, it is difficult to improve the allocative efficiency of scarce financial resources.

The WHO-CHOICE [45] has suggested thresholds between one and three times GDP per capita for a year of perfect health gained to guide policymakers on value for money [45]. However, recently WHO researchers have also stated that WHO had not recommended that three times GDP for a year of perfect health gained be considered 'relatively' cost effective [46]. A recent brief report demonstrated growing use and misuse of 1-3 times GDP per capita CETs in low- and middle-income countries without examining the criteria in a local context and encouraged practitioners to develop CETs reflecting local priorities [47]. Several studies [12, 48-51] have called for developing consensus on the estimation and use of CETs.

The value of the CET in the countries examined is in the range of 1-3 times the per capita GDP. CEE countries are in the upper range and their CETs are linked to the GDP per capita (or similar economic indicator, such as the average wage in Slovakia). Some more affluent Western European countries tend to use CET in the lower range, and their thresholds are not linked to economic indicators, in other words CETs are not increased automatically if the economy grows (which was the case in recent years before the COVID pandemic). In the European countries CETs have been increasing in fairly rapidly growing economies in CEEs in recent years, CETs in CEE countries have been overtaking CETs in Western European countries not even relatively to the GDP per capita, but even in absolute terms. The CETs in Hungary, Poland and Czech Republic are $€ 39,540$, $€ 33,188$ and $€ 44,834$ respectively, while in the UK it is only $€ 22,400-€ 33,600$, whilst GDP per capita in Hungary, Poland and Czech Republic is 40\%, 39\% and $55 \%$ of GDP in the UK, respectively. An important consequence of a high CET is the ineffective price control mechanism of new health technologies. Data show that prices paid in Poland for certain pharmaceuticals appear to be higher than the mean values for the European Union $[51,52]$.

As shown in Tables 1 and 2, multiple CETs have been introduced in several countries to overcome the disadvantages and limitations of using a single CET. While ICERs are certainly informative in assessing value for money, they need to be considered alongside affordability, fairness, feasibility and other criteria deemed important in the local context. Prioritization decisions in practice often include other considerations than just efficiency. The assumption that all units of health gain have equal social value, also referred to as 'a QALY is a QALY is a QALY' [53], has already been debated heavily in the health economics literature [31, 34, 35, 40, 54-56]. Society may be willing to pay more for treating life-threatening diseases such as cancer $[57,58]$, than for treating a self-limiting or chronic disease that does not seriously compromise daily living. To provide a more quantifiable framework for prioritization, multiple thresholds are being introduced.

There are three main approaches to determine CETs [44]: the willingness-to-pay (WTP) method for a unit of outcome; the opportunity cost method, which links the threshold to the volume of health displaced by new technologies when budget constraints are taken into account; and the precedent method based on the value of a technology already funded [59-61]. In the absence of such recent studies in Hungary, the Threshold Working Group decided to benchmark Hungary with other countries where a well-established HTA system exists. The Working Group concluded that a more restrictive application of the CET and the prioritization for higher relative QALY gains and rare diseases may be needed in Hungary. The use of the IRQG as an equity weight has been tested only on historical data, and it is difficult to foresee how its use will influence the chosen economic evaluation methods by pharmaceutical companies in the HTA dossier. Consequently, the Committee recommends monitoring the comparison of IRQGs in past and future economic evaluations in HTA dossiers and revising the methodology if necessary.

The results of the present study are in line with recommendations of recent publications [44, 47] that countries should make individual efforts to propose a threshold based on the local context. To this end, social preferences, economic constraints of the country, observed trends in other countries in the region, and the maturity of the HTA system need to be taken into account.

The strength of our paper is that we have managed to extract information on CETs in CEE countries (e.g., Latvia, Lithuania), in addition to those which are regularly included in the literature. This way we could provide a more comprehensive picture on CEE countries. The proposal presented in this paper might have some important policy implications in Hungary. We believe that introducing lower CETs for medicines in common diseases with less relative health gain will lead to more appropriate pricing of new technologies and will increase the efficiency of budget allocation. The use of IRQG to determine the value of the CET is anticipated to prioritise the adoption of 
technologies that produce higher relative health benefits. Access to orphan medicines on the positive drug list is likely to improve, as technologies that are accessible only on a named patient basis can be officially listed. The role of the HTA is expected to be strengthened in terms of serving as a primary filter for selecting technologies that are worth funding. Applying the new CETs also creates a stronger negotiating position and might increase bargaining power of the payer. Pharmaceutical companies that can bring cost-effective technologies to market are less likely to face budgetary constraint because the less cost-effective technologies will not use up the available budget.

A limitation of our proposal is that the CETs have not been derived empirically, as no information was available on the ICERs of past decisions or on the willingness-topay, and no underlying data were accessible to estimate the opportunity costs. Therefore, the best available approach was to draw conclusions from the practices of other countries and develop recommendations by involving a wide group of HTA experts. The proposal has been endorsed by the Ministry of Human Capacities in November 2021 [62]. It is highly recommended to review the initial experiences in the first years, and amend the CETs, if needed. In addition, in the absence of any studies explicitly investigating the preferences of the population, the appropriateness of adjusting the CET in relation to the relative health gain remains an assumption.

We are aware of the methodological weaknesses of cost-effectiveness analyses and also want to emphasise that considering the cost-effectiveness of a technology is necessary, but it is not the sole basis for decision-making. We advocate making as much data as possible on costeffectiveness results publicly available, taking uncertainties into account, and making reimbursement decisions more transparent and accountable.

\section{Conclusion}

Threshold values in relation to the GDP per capita vary widely between countries. Multi-level thresholds can be set to reflect different preferences of resource allocation in healthcare funds providing selective advantage for specialised technologies. CETs should be aligned with the country's economic performance and should reflect societal preferences. Our recommendation may increase the efficiency and equity of healthcare resource allocation in Hungary by strengthening the role of HTA in the reimbursement decisions of new technologies.

Supplementary Information The online version contains supplementary material available at https://doi.org/10.1007/s40258-021-00710-z.
Acknowledgements We would like to thank all members of the ISPOR Hungary Chapter Threshold Working Group and the Guideline Revision Committee for their reflections on the results of the literature research and web search as well as for their contributions to the drafting of the proposal for CET.

\section{Declarations}

Funding Open access funding provided by University of Pécs. This study received no funding.

Conflicts of Interest None of the authors have any potential conflicts of interest.

Ethics approval Not applicable.

Consent to participate Not applicable.

Consent for publication Not applicable.

Availability of data and material Not applicable.

Code availability Not applicable.

Authors' Contributions SK conducted a review of the guidelines and drafted the first version of the manuscript. BN and DE contributed to the screening and review of the guidelines. $\mathrm{ZK}$ advised on the interpretation of the review findings. SK, VB, IB, ZK and AZ and participated in the development of the proposal. VB, ZK and IB critically reviewed the manuscript. AZ conceptualised the review, coordinated the development of the proposal, and drafted the final version of the paper. All authors approved the final versions as submitted.

Open Access This article is licensed under a Creative Commons Attribution-NonCommercial 4.0 International License, which permits any non-commercial use, sharing, adaptation, distribution and reproduction in any medium or format, as long as you give appropriate credit to the original author(s) and the source, provide a link to the Creative Commons licence, and indicate if changes were made. The images or other third party material in this article are included in the article's Creative Commons licence, unless indicated otherwise in a credit line to the material. If material is not included in the article's Creative Commons licence and your intended use is not permitted by statutory regulation or exceeds the permitted use, you will need to obtain permission directly from the copyright holder. To view a copy of this licence, visit http://creativecommons.org/licenses/by-nc/4.0/.

\section{References}

1. Cubi-Molla P, Errea M, Zhang K, Garau M. Are cost-effectiveness thresholds fit for purpose for real-world decision making? OHE Consulting Report, London; 2020.

2. Szende Á, Mogyorósy Z, Muszbek N, Nagy J, Pallos G, Dözsa C. Methodological guidelines for conducting economic evaluation of healthcare interventions in Hungary: a Hungarian proposal for methodology standards. Eur J Health Econ. 2002;3(3):196-206.

3. Kaló Z, et al. Capacity building for HTA implementation in middle-income countries: the case of Hungary. Value Health Reg Issues. 2013;2(2):264-6. 
4. Ministry of Human Resources. Az Emberi Erőforrások Minisztériuma szakmai irányelve az egészségügyi technológia értékelés módszertanáról és ennek keretében költséghatékonysági elemzések készítésérôl. (Guidelines On the methodology of health technology assessment and economic evaluatio. Egészségügyi Közlöny. 2017;66(3):821-42.

5. National Institute for Health and Clinical Excellence, Guide to the methods of technology appraisal 2008, London; 2008. https://doi. org/10.2165/00019053-200826090-00002.

6. Eurostat, ECU/€ exchange rates versus national currencies; 2021.https://ec.europa.eu/eurostat/databrowser/view/tec00033/ default/table?lang=en.

7. National Institute For Health And Care Excellence Centre For Health Technology Evaluation, Value based assessment of health technologies introduction-consultation paper; 2014. https:// www.nice.org.uk/Media/Default/About/what-we-do/NICE-guida nce/NICE-technology-appraisals/VBA-TA-Methods-Guide-forConsultation.pdf.

8. National Institute for Health and Care Excellence, Guide to the methods of technology appraisal 2013; 2013. https://www.nice. org.uk/process/pmg9/chapter/the-appraisal-of-the-evidence-andstructured-decision-making.

9. National Institute for Health and Care Excellence, Changes to NICE drug appraisals: what you need to know; 2017. https:// www.nice.org.uk/news/feature/changes-to-nice-drug-appra isals-what-you-need-to-know.

10. Erostat. Main GDP aggregates per capita. 2021. http://appsso. eurostat.ec.europa.eu/nui/show.do?dataset=nama_10_pc\& lang=en.

11. Culyer AJ. Cost-effectiveness thresholds in health care: a bookshelf guide to their meaning and use. Health Econ Policy Law. 2016;11(4):415-32.

12. Woods B, Revill P, Sculpher M, Claxton K. Country-level costeffectiveness thresholds: initial estimates and the need for further research. Value Health. 2016;19(8):929-35.

13. Inotai $\mathrm{A}$, et al. Identifying patient access barriers for tumor necrosis factor alpha inhibitor treatments in rheumatoid arthritis in five central eastern European countries. Front Pharmacol. 2020;11:845.

14. Inotai A, Kaló Z. How to solve financing gap to ensure patient access to patented pharmaceuticals in CEE countries? The good, the bad, and the ugly ways. Expert Rev Pharmacoecon Outcomes Res. 2019;19(6):627-32.

15. Németh B, Kaló Z. European cooperation in health technology assessment implementation: the perspective of Central and Eastern European countries. J Comp Eff Res. 2020;9(9):599-602.

16. Szegedi M, et al. The European challenges of funding orphan medicinal products. Orphanet J Rare Dis. 2018;13(1):184.

17. Grigore B, et al. Surrogate endpoints in health technology assessment: an international review of methodological guidelines. Pharmacoeconomics. 2020;38:1055-70.

18. Státní Ústav Pro Kontrolu Léčiv, Postup pro posuzování analýzy nákladové efektivity (Procedure for assessing cost - effectiveness analysis); 2020. https://www.sukl.cz/file/92848_1_1.

19. Health Information and Quality Authority, Guidelines for the economic evaluation of Health Technologies in Ireland; 2019. https://www.hiqa.ie/sites/default/files/2020-09/HTA-EconomicGuidelines-2020.pdf.

20. Republic of Latvia, Procedures for the reimbursement of expenditures for the acquisition of medicinal products and medical devices intended for the outpatient medical treatment; 2018. https://likumi.lv/ta/en/en/id/147522-procedures-for-the-reimb ursement-of-expenditures-for-the-acquisition-of-medicinalproducts-and-medical-devices-intended-for-the-outpatientmedical-treatment.
21. Minister Of Health Of The Republic Of Lithuania, Order approval of the benefit value of the reference cost; 2020. https:// www.e-tar.lt/portal/lt/legalAct/a35e84704e4211ea8aceeadd0 c5b168c.

22. Norwegian Ministry of Health and Care Services, Principles for priority setting in health care-summary of a white paper on priority setting in the Norwegian health care sector; 2017. https://www.regjeringen.no/contentassets/439a420e01914a1 8b21f351143ccc6af/en-gb/pdfs/stm201520160034000engpdfs. pdf.

23. Agencja Oceny Technologii Medycznych i Taryfikacji, Wytyczne oceny technologii medycznych (Health Technology Assessment Guidelines); 2016. https://www2.aotm.gov.pl/wp-content/ uploads/wytyczne_hta/2016/20160913_Wytyczne_AOTMiT. pdf.

24. Ministry of Health Slovakia, Decree of the Ministry of Health of the Slovak Republic on the criteria for determining the significance of the effect of a medicinal product on public health insurance funds, on the evaluation criteria for the calculation of the threshold coefficient; 2018.

25. Health Insurance Institute of Slovenia, Sklep o dolocitvi mejnega razmerja stroskovne učinkovitosti (Decision on setting the cost-effectiveness ratio); 2013.

26. Swedish Agency For Health Technology Assessment And Assessment Of Social Services,Assessment of methods in health care and social services; 2018.

27. Zorginstituut Nederland, Cost-effectiveness in practice; 2015.

28. Eurostat. Real GDP per capita. 2020. https://ec.europa.eu/euros tat/databrowser/view/sdg_08_10/default/table?lang=en.

29. Brouwer W, van Baal P, van Exel J, Versteegh $M$. When is it too expensive? Cost-effectiveness thresholds and health care decision-making. Eur J Health Econ. 2019;20(2):175-80.

30. OECD, E. Union. Health expenditure per capita; 2020.

31. Dolan P, Shaw R, Tsuchiya A, Williams A. QALY maximisation and people's preferences: a methodological review of the literature. Health Econ. 2005;14(2):197-208.

32. Stolk EA, Pickee SJ, Ament AHJA, Busschbach JJV. Equity in health care prioritisation: an empirical inquiry into social value. Health Policy. 2005;74(3):343-55.

33. Tsuchiya A, Dolan P. Equality of what in health? Distinguishing between outcome egalitarianism and gain egalitarianism. Health Econ. 2009;18(2):147-59.

34. Schwappach DLB. Resource allocation, social values and the QALY: a review of the debate and empirical evidence. Health Expect Int J Public Particip Health Care Health Policy. 2002;5(3):210-22.

35. Bobinac A, van Exel NJA, Rutten FFH, Brouwer WBF. "Inquiry into the relationship between equity weights and the value of the QALY. Value Health J Int Soc Pharmacoecon Outcomes Res. 2012;15(8):1119-26.

36. Bleichrodt H, Diecidue E, Quiggin J. Equity weights in the allocation of health care: the rank-dependent QALY model. J Health Econ. 2004;23(1):157-71.

37. Paris/European Observatory on Health Systems and Policies. Hungary: Country Health Profile 2017, State of Health in the EU, Brussels; 2017.

38. Reckers-Droog VT, van Exel NJA, Brouwer WBF. Looking back and moving forward: on the application of proportional shortfall in healthcare priority setting in the Netherlands. Health Policy. 2018;122(6):621-9.

39. Miners A, Cairns J, Wailoo AJ. Department of health proposals for including burden of illness into value based pricing: a description and critique; 2013. pp. 1-33.

40. van de Wetering EJ, Stolk EA, van Exel NJA, Brouwer WBF. Balancing equity and efficiency in the Dutch basic benefits package 
using the principle of proportional shortfall. Eur J Health Econ. 2013;14(1):107-15.

41. Zelei T, Molnár MJ, Szegedi M, Kaló Z. Systematic review on the evaluation criteria of orphan medicines in Central and Eastern European countries. Orphanet J Rare Dis. 2016;11(1):72.

42. Simoens S, Picavet E, Dooms M, Cassiman D, Morel T. Costeffectiveness assessment of orphan drugs: a scientific and political conundrum. Appl Health Econ Health Policy. 2013;11(1):1-3.

43. Berdud M, Drummond M, Towse A. Reasonable price for an orphan drug establishing a reasonable price for an orphan drug; 2018. https://resource-allocation.biomedcentral.com/articles/10. 1186/s12962-020-00223-X.

44. Santos AS, Guerra-Junior AA, Godman B, Morton A, Ruas CM. Cost-effectiveness thresholds: methods for setting and examples from around the world. Expert Rev Pharmacoecon Outcomes Res. 2018;18(3):277-88.

45. WHO Commission on Macroeconomics and Health. Macroeconomics and health : investing in health for economic development/ report of the Commission on Macroeconomics and Health; 2001.

46. Garner S, Rintoul A, Hill SR. Value-Based Pricing: L'Enfant Terrible? Pharmacoeconomics. 2018;36(1):5-6.

47. Leech AA, Kim DD, Cohen JT, Neumann PJ. Use and misuse of cost-effectiveness analysis thresholds in low- and middleincome countries: trends in cost-per-DALY studies. Value Health. 2018;21(7):759-61.

48. Robinson LA, Hammitt JK, Chang AY, Resch S. Understanding and improving the one and three times GDP per capita cost-effectiveness thresholds. Health Policy Plan. 2017;32(1):141-5.

49. Shillcutt SD, Walker DG, Goodman CA, Mills AJ. Cost effectiveness in low- and middle-income countries: a review of the debates surrounding decision rules. Pharmacoeconomics. 2009;27(11):903-17.

50. Ochalek J, Lomas J, Claxton K. Estimating health opportunity costs in low-income and middle-income countries: a novel approach and evidence from cross-country data. BMJ Glob Health. 2018;3(6):e000964.
51. Bertram MY, et al. Cost-effectiveness thresholds: pros and cons. Bull World Health Organ. 2016;94(12):925-30.

52. Iyengar $\mathrm{S}$, et al. Prices, costs, and affordability of new medicines for hepatitis $\mathrm{C}$ in 30 countries: an economic analysis. PLoS Med. 2016;13(5):e1002032.

53. Weinstein MC. A QALY is a QALY —or is it? J Health Econ. 1988;7(3):289-90.

54. Cookson R, Drummond M, Weatherly H. Explicit incorporation of equity considerations into economic evaluation of public health interventions. Health Econ Policy Law. 2009;4(Pt 2):231-45.

55. Wagstaff A, van Doorslaer E. Measuring and testing for inequity in the delivery of health care. J Hum Resour. 2000;35(4):716-33.

56. Nord E. The person-trade-off approach to valuing health care programs. Med Decis Mak Int J Soc Med Decis Mak. 1995;15(3):201-8.

57. Round J. Is a QALY still a QALY at the end of life? J Health Econ. 2012;31(3):521-7.

58. de Groot F, et al. Ethical hurdles in the prioritization of oncology care. Appl Health Econ Health Policy. 2017;15(2):119-26.

59. Haji-Ali-Afzali H, Karnon J, Sculpher M. Should the lambda $(\lambda)$ remain silent? Pharmacoeconomics. 2016;34(4):323-9.

60. Vallejo-Torres L, García-Lorenzo B, Serrano-Aguilar P. Estimating a cost-effectiveness threshold for the Spanish NHS. Health Econ. 2018;27(4):746-61.

61. Paulden M, O'Mahony J, McCabe C. Determinants of change in the cost-effectiveness threshold. Med Decis Mak Int J Soc Med Decis Mak. 2017;37(2):264-76.

62. Ministry of Human Capacities, Egészség-gazdaságtani egészségügyi szakmai irányelv az egészség-gazdaságtanielemzések készítéséhez és értékeléséhez (Health Economic Guidelines for the Preparation and Evaluation of Economic Evaluations), Egészségügyi Közlöny. 2021;21:2178-2200. http://metaweb.hu/ wp-content/uploads/Eggazd_iranyelv_2021-2024.pdf. 